\title{
SUB-ARACHNOID BLOCK FOR AN ELDERLY PATIENT WITH CHRONIC RENAL FAILURE, RIGHT SIDE LOCULATED PNEUMOTHORAX AND WITH COMPLETE HEART BLOCK ON PACEMAKER
}

Krishna Prabu R ${ }^{1}$, Gunaseelan S²

\section{HOW TO CITE THIS ARTICLE:}

Krishna Prabu R, Gunaseelan S. "Sub-Arachnoid Block for an Elderly Patient with Chronic Renal Failure, Right Side Loculated Pneumothorax and with Complete Heart Block on Pacemaker". Journal of Evolution of Medical and Dental Sciences 2014; Vol. 3, Issue 20, May 19; Page: 5597-5600, DOI: 10.14260/jemds/2014/2635

ABSTRACT: Patients presenting for an elective or emergency surgery with pre-existing chronic renal failure (CRF) has certain anesthetic considerations. Central neuraxial block for these patients is controversial, because all these patients will be invariably on fluid restriction. If such patient presents with pulmonary complications and cardiac complications which are relative contraindications for general anesthesia then the anesthetic management becomes trickier. We had a patient with CRF, presented with inter-trochanteric fracture of femur for surgical fixation. The patient also had left side loculated pneumothorax, right side bronchiectatic changes and permanent cardiac pacemaker for complete heart block which were challenges for general anesthesia too. Finally the surgery was done under central neuraxial block with dopamine support successfully.

KEYWORDS: Surgery, Renal failure, cardiac, pulmonary, complications.

INTODUCTION: Patients with CRF subjected for surgery generally presents with fluid and electrolyte imbalance. Most of these patients will be on regular dialysis and on fluid restriction. Central neuraxial block is tricky in these patients because hypotension following sub-arachnoid block cannot be treated with fluid boluses. ${ }^{1}$ So general anesthesia is preferred in these patients. Elderly patients with CKD subjected for fracture femur surgery has poor outcome because of associated perioperative complications ${ }^{2}$. We are reporting the anesthetic management of a CRF patient presented with intertrochanteric fracture of right femur. The patient also had loculated pneumothorax on left lung, bronchiectatic changes on right lung and a cardiac pacemaker for complete heart block. The lung pathologies were not favorable for general anesthesia and sub-arachnoid block was chosen as an anesthetic technique with some precautions and modifications.

CASE REPORT: 82yr male presented to our casualty with history of fall and pain in right hip. X-ray hip antero-posterior view revealed inter-trochanteric fracture of right femur. The patient was a known case of CRF on thrice weekly dialysis and on $300 \mathrm{ml}$ fluid restriction per day. The patient was evaluated for a fainting attack 4years back, diagnosed to have complete heart block and was put on permanent pacemaker. The patient was admitted 4 months back with dyspnea and diagnosed to have left side massive empyema thorax for which inter-costal drain (ICD) was inserted. But the collapsed lung did not expand after ICD and left with loculated pneumothorax.

On examination patient was conscious, oriented, afebrile, dyspnoeic and hemodynamically stable. Room air saturation $\left(\mathrm{SpO}_{2}\right)$ was $92 \%$. Cardiovascular system was normal. Diffuse crepitations were present on left side lung zones and right upper zone. The patient had dialysis two days prior to admission. On investigation hemoglobin was 8.2gms\%, urea-102 $\mathrm{mg} \%$, creatinine-3, potassium$4.5 \mathrm{meq} / \mathrm{l}$ and INR-1.3. Chest X-ray revealed loculated pneumothorax on left side, and bronchiectatic changes on right side (Figure-1). Pulmonary function test revealed a restrictive lung disease pattern ${ }^{3}$. 
Pacemaker's pulse generator and lead position were also confirmed on chest X-ray (Figure-1). Other investigations were within normal limits.

As part of preparation pacemaker was checked by cardiologist and was put on asynchronous mode. With heparin free dialysis 1.5 litres of fluid was removed on the night before surgery. After fluid removal patient was comfortable at rest and room air saturation was $99 \%$. Adequate blood was arranged. Informed high risk consent was obtained from the patient.

Considering the pulmonary complications general anesthesia was deferred in our patient. Epidural anesthesia was deferred because of marginally elevated INR. We were left out with an option of sub-arachnoid block. Standard monitoring was done with ECG, Pulse oximetry, Blood pressure (B.P) and Respiratory rate. Baseline B.P was $124 / 72$, Heart rate was $84 / \mathrm{min}$ and $\mathrm{SpO}_{2}$ was $98 \%$. Combination of $2 \mathrm{ml}$ of $0.5 \%$ bupivacaine and $0.5 \mathrm{ml}$ (25micrograms) of fentanyl was used for sub-arachnoid block, which was performed with 27 gauge spinal needle. Sensory level of T10 (i.e. up to the level of umbilicus) was achieved. 5 minutes after sub-arachnoid block blood the B.P dropped to $70 / 40 \mathrm{~mm}$ hg which was treated with $6 \mathrm{mg}$ of ephedrine.

But B.P increased only up to 85/46 $\mathrm{mm}$ hg. Since fluid cannot be rushed in this patient Dopamine infusion was started at the rate of 15 microgram $/ \mathrm{kg}$ body weight, following which blood pressure picked up to 115/80 mm hg. After that B.P was stable throughout. A 10 degree head down was given 20 minutes after sub-arachnoid block to improve venous return. Towards end of surgery B.P increased to $140 / 90 \mathrm{~mm}$ hg and dopamine infusion was tapered to 10 microgram $/ \mathrm{kg}$ body weight.

Bipolar diathermy in short bursts was used for hemostasis to avoid pacemaker interference. Dynamic hip screw fixation was done with 75 minutes surgical time.

Intra-operative blood loss was about $200 \mathrm{ml}$. Patient was shifted to critical care unit for postoperative monitoring. Dopamine infusion was tapered at the rate of 2 microgram $/ \mathrm{kg}$ body weight per hour and stopped after 5hours. Post-operative period was uneventful.

DISCUSSSION: General anesthesia is the technique of choice in patients with CRF posted for lower abdominal and lower limb surgeries. But, if these patients have associated pulmonary complications, then anesthesiologists are left with a choice of regional anesthesia. Sub-arachnoid block with 27 or 26 gauge spinal needle is generally preferred over epidural block, since these patients have altered platelet function and prolonged prothrombin time. ${ }^{4}$

The commonest complication associated with central neuraxial block is hypotension, which is treated with fluid and vasopressors. But patients with CRF on regular hemodialysis will be on 200 to $300 \mathrm{ml}$ fluid restriction per day. Fluid bolus in these patients can cause fluid overload and pulmonary edema. Hence, hypotension is treated with vasopressors in these patients. Since these patients are volume depleted there will be a poor response to vasopressors. Dopamine which is an inotropic and vasoconstrictor at higher dosage is the next alternative. ${ }^{5}$

Our patient had loculated pneumothorax on one side and bronchiectatic changes on other side of lung, because of which general anesthesia was deferred and anticipating intraoperative deterioration of lung function surgery was done under sub-arachnoid block. ${ }^{6}$ Following subarachnoid block patient had hypotension, which poorly responded to vasopressors. With dopamine in dose of 15 microgram/kg body weight B.P was stabilized and anesthesia was uneventful after that. There was increase in heart rate by 15 beats per minute which was well tolerated by the patient. 
Hence we conclude that dopamine is a safer alternative over vasopressors and fluids in CRF patients undergoing surgery under sub-arachnoid block.

\section{CONCLUSIONS:}

1. Elderly patient with CRF is not an ideal candidate for sub-arachnoid block because hypotension cannot be treated with fluid boluses.

2. But, when the patient has got some contraindications to general anaesthesia then regional anaesthesia is the choice.

3. CRF patients have poor response to vasopressors because these patients are generally volume depleted.

4. Hypotension during sub-arachnoid block in these patients can be better managed with high dose of dopamine, since it has got both inotropic and vasopressor effect.

\section{REFERENCES:}

1. Yi-Chun Tsai et al. Association of fluid overload with kidney disease progression in advanced CKD: A prospective cohort study. American Journal of Kidney Diseases. 2014 Jan; 63 (1):68-75.

2. Sameer K Khan, Stephen P Rushton, Michael Courtney, Andrew C Gray, David J Dehan. Elderly men with renal dysfunction are most at risk for poor outcome after of neck of femur fractures. Age Ageing. 2012 Oct; 42 (1):76-81.

3. Luiza Helena Degani-Costa, Sonia Maria Faresin, Luiz Fernando dos Reis Falcao. Preoperative evaluation of the patient with pulmonary disease. Brazilian Journal of Anesthesiology. 2014 Jan; 64 (1): 22-24.

4. Azuma K, Nakamoto T, Terai T, Nishikawa K, Yukioka H, Fujimori M. Cesarian section under spinal anesthesia for a patient with chronic renal failure. Masui. 1996 Jul; 45(7): 880-3.

5. Arai M. Perioperative respiratory and circulatory management for chronic kidney disease. Masui. 2013 Nov; 62(1):1313-9.

6. Nymam AG, Sonnappa S, Prendiville AT, Jaffe A. Ventilation induced pneumothorax following resolved empyema. Pediatr Pulmonol. 2008 Jan; 43(1):99-101. 


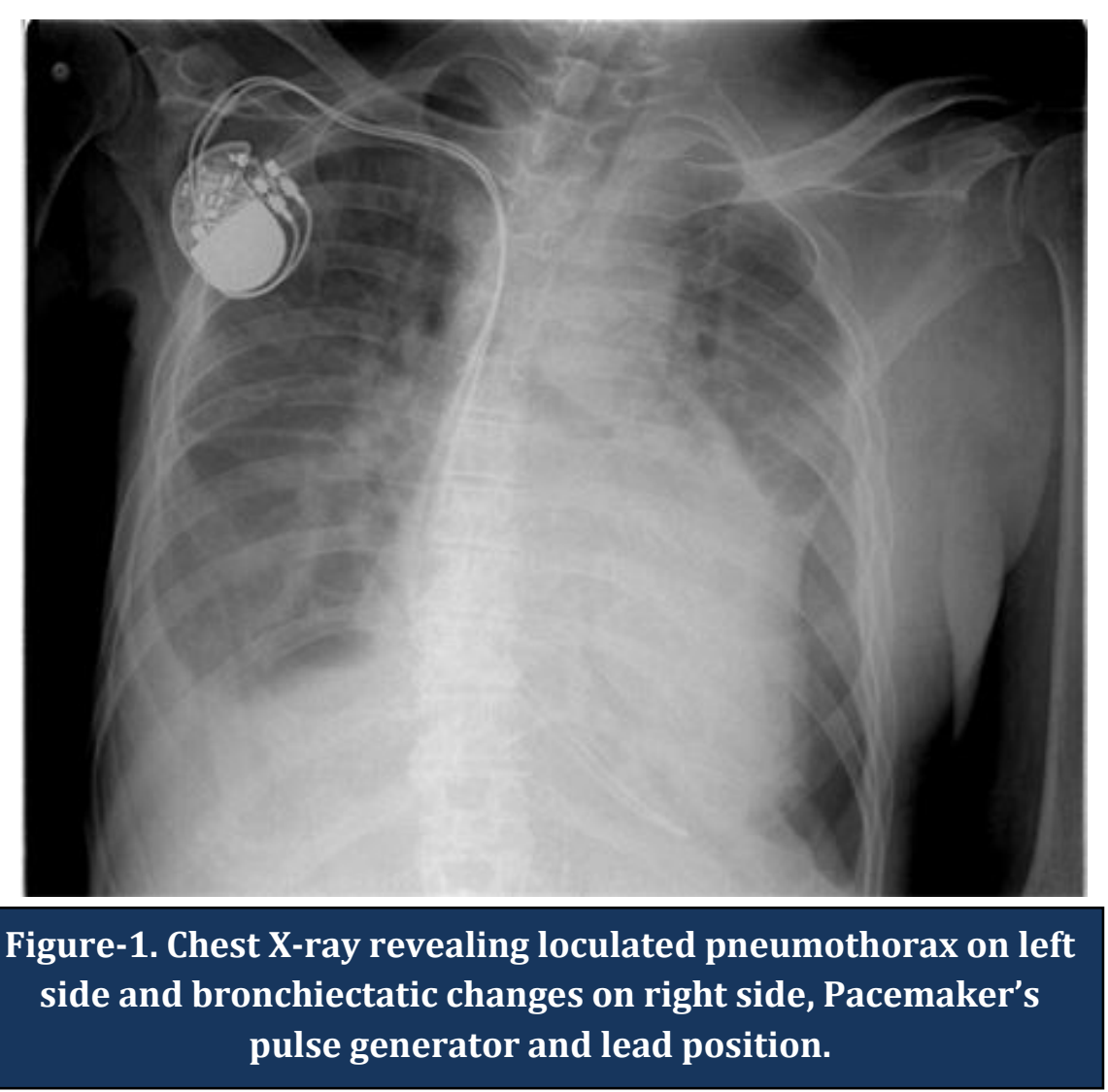

\section{AUTHORS:}

1. Krishna Prabu R.

2. Gunaseelan S.

\section{PARTICULARS OF CONTRIBUTORS:}

1. Associate professor, Department of Anaesthesiology, Sri Venkateshwarra Medical College Hospital and Research Centre.

2. Assistant Professor, Department of Anaesthesiology, Sri Venkateshwarra Medical College Hospital and Research Centre.

\section{NAME ADDRESS EMAIL ID OF THE CORRESPONDING AUTHOR: \\ Dr. R. Krishna Prabu, \\ Associate Professor, \\ Department of Anaesthesiology, Sri Venkateshwarra Medical College and Research Center. \\ Ariyur, Puducherry. \\ Email: drkrishnaprabu@gmail.com}

Date of Submission: 26/04/2014.

Date of Peer Review: 27/04/2014.

Date of Acceptance: 07/05/2014.

Date of Publishing: 19/05/2014. 